Article

\title{
Enthalpy of Mixing in Al-Tb Liquid
}

\author{
Shihuai Zhou ${ }^{1}$, Carl Tackes ${ }^{2}$ and Ralph Napolitano ${ }^{1,2, *}$ \\ 1 Division of Materials Science and Engineering, Ames Laboratory, United States Department of Energy, \\ Ames, IA 50011, USA; szhou@ameslab.gov \\ 2 Department of Materials Science and Engineering, Iowa State University, Ames, IA 50011, USA; \\ carltackes@gmail.com \\ * Correspondence: ren1@iastate.edu; Tel.: +1-515-294-9101
}

Received: 10 April 2017; Accepted: 15 June 2017; Published: 21 June 2017

\begin{abstract}
The liquid-phase enthalpy of mixing for Al-Tb alloys is measured for 3, 5, 8, 10, and $20 \mathrm{at} \% \mathrm{~Tb}$ at selected temperatures in the range from 1364 to $1439 \mathrm{~K}$. Methods include isothermal solution calorimetry and isoperibolic electromagnetic levitation drop calorimetry. Mixing enthalpy is determined relative to the unmixed pure $(\mathrm{Al}$ and $\mathrm{Tb})$ components. The required formation enthalpy for the $\mathrm{Al}_{3} \mathrm{~Tb}$ phase is computed from first-principles calculations. Based on our measurements, three different semi-empirical solution models are offered for the excess free energy of the liquid, including regular, subregular, and associate model formulations. These models are also compared with the Miedema model prediction of mixing enthalpy.
\end{abstract}

Keywords: Al-Tb; mixing; enthalpy; electromagnetic levitation; solution calorimetry

\section{Introduction}

Phase selection pathways in glass-forming metallic liquids are influenced by the development of short- and medium-range order [1-10], which contribute to local energetics and dynamics. Even in binary glass-forming systems, clear evidence of the influence of ordering in the liquid state has been reported [3-5,11-17]. For example, the marginal glass-forming ability in the Al-RE (aluminum rare-earth) systems has been associated with ordering in the liquid phase [18-29]. In addition, due to their relative simplicity compared to conventional many-component glass-forming alloys, Al-RE and Al-RE-TM (TM denotes transition metal) alloys are excellent model systems for the investigation of phase stability [30-33], metallic glass formation [34-37], liquid properties and crystallization [38-40], and glassy alloy structure/properties [25,41,42]. As with all glass-forming liquids, however, properties may become increasingly temperature dependent near and below the liquidus [43-45], highlighting the need for reliable thermodynamic descriptions of the liquid state. Numerous theoretical/computational studies, thermodynamic assessments, and associated CALPHAD models for the Al-RE systems are available [32,33,46-50], but reported experimental measurements of excess mixing quantities for Al-RE liquids are very limited, as listed for the Al-lanthanides in Table 1.

Table 1. A listing of thermodynamic mixing property measurements, calculations, and phase diagram assessments reported for the Al-RE (lanthanide) binary systems.

\begin{tabular}{cccc}
\hline System & $\begin{array}{c}\text { CALPHAD } \\
\text { Assessments }\end{array}$ & $\begin{array}{c}\text { FP Calculations of } \\
\text { Crystal Phase Energies }\end{array}$ & $\begin{array}{c}\text { Experimental Measurement of } \\
\text { Liquid Mixing Properties }\end{array}$ \\
\hline $\mathrm{Al}-\mathrm{La}$ & {$[51,52]$} & {$[53,54]$} & {$[55-57]$} \\
$\mathrm{Al}-\mathrm{Ce}$ & {$[52,58,59]$} & {$[53]$} & {$[60-62]$} \\
$\mathrm{Al}-\mathrm{Pr}$ & {$[52,63]$} & {$[53]$} & {$[63,64]$} \\
$\mathrm{Al}-\mathrm{Nd}$ & {$[52,58]$} & {$[53]$} & {$[64]$} \\
$\mathrm{Al}-\mathrm{Pm}$ & - & {$[53]$} & - \\
$\mathrm{Al}-\mathrm{Sm}$ & {$[52,65]$} & {$[53,66]$} & {$[67]$} \\
\hline
\end{tabular}


Table 1. Cont.

\begin{tabular}{cccc}
\hline System & $\begin{array}{c}\text { CALPHAD } \\
\text { Assessments }\end{array}$ & $\begin{array}{c}\text { FP Calculations of } \\
\text { Crystal Phase Energies }\end{array}$ & $\begin{array}{c}\text { Experimental Measurement of } \\
\text { Liquid Mixing Properties }\end{array}$ \\
\hline $\mathrm{Al}-\mathrm{Eu}$ & - & {$[53]$} & - \\
$\mathrm{Al}-\mathrm{Gd}$ & {$[68-70]$} & {$[53]$} & {$[71,72]$} \\
$\mathrm{Al}-\mathrm{Tb}$ & {$[69]$} & {$[53]$} & - \\
$\mathrm{Al}-\mathrm{Dy}$ & {$[69,73]$} & {$[53]$} & - \\
$\mathrm{Al}-\mathrm{Ho}$ & {$[69]$} & {$[53]$} & - \\
$\mathrm{Al}-\mathrm{Tm}$ & - & {$[53]$} & - \\
$\mathrm{Al}-\mathrm{Yb}$ & {$[74]$} & {$[53]$} & - \\
$\mathrm{Al}-\mathrm{Lu}$ & - & {$[53]$} & - \\
\hline
\end{tabular}

In the current work, we focus on the $\mathrm{Al}-\mathrm{Tb}$ binary system (see Figure 1) and make critical measurements of the enthalpy of mixing, $\Delta H_{\text {mix }}$, for the liquid phase. Specifically, we perform solution calorimetry and electromagnetic levitation drop calorimetry to measure $\Delta H_{\text {mix }}$ in dilute $\mathrm{Al}-\mathrm{Tb}$ alloys with $\mathrm{Tb}$ content up to $x_{T b}=0.2$ (mole fraction). In addition, we compare three different semi-empirical solution models for the excess free energy of the liquid, incorporating regular, subregular, and associate [75] formulations for the mixing enthalpy. These are compared with the Miedema model [76-78] for this system.

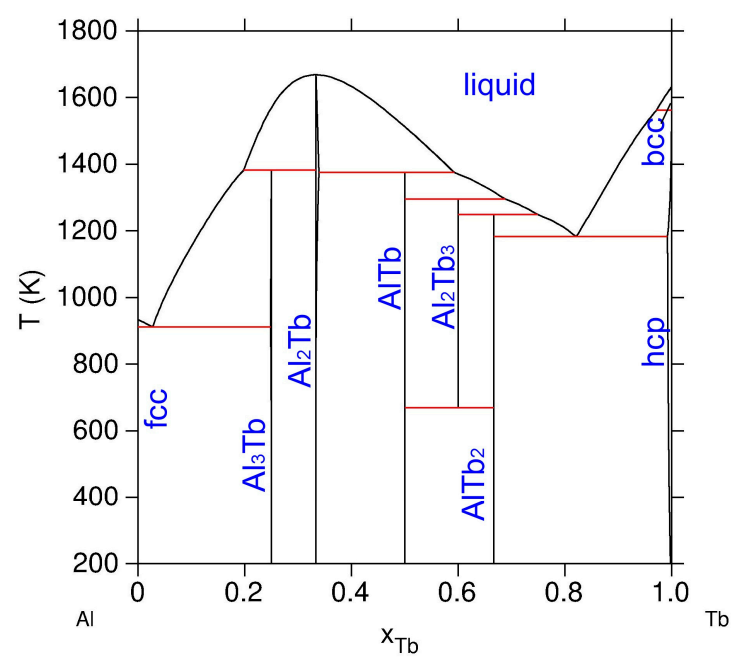

Figure 1. The assessed $\mathrm{Al}-\mathrm{Tb}$ phase diagram.

\section{Calorimetry Experiments}

We employ here two different calorimetric techniques to determine $\Delta H_{m i x}$ for the Al-Tb liquid phase in the stable temperature range. Using an isothermal solution calorimetry (ISC) method, we measure the thermal transient associated with the dissolution of a small amount of $\mathrm{Tb}$ in a liquid Al solvent, permitting direct determination of $\Delta H_{m i x}$ for the liquid phase. Using an electromagnetic levitation drop calorimetry (EMLDC) method, we measure the heat evolved upon rapid cooling of the high temperature equilibrium alloy liquid to a low temperature multi-phase state, from which we determine the high temperature mixing enthalpy, $\Delta H_{m i x}$. All test specimens were prepared from the pure elemental components $(0.9999 \mathrm{Al}$ and $0.999 \mathrm{~Tb}$, by weight (pure $\mathrm{Al}$ and $\mathrm{Tb}$ were supplied by Cerac, Inc., Milwaukee, WI, USA)). Alloy specimens of desired composition were prepared for EMLDC by arc melting the pure components five times in succession on a water-cooled copper hearth under a high-purity (ultra-high purity $(99.999 \%)$ argon, supplied by Matheson Company, Des Moines, IA, USA) argon atmosphere. Test specimens were then cut to the desired size using a diamond saw. 
The central components of the custom-built ISC are illustrated schematically in Figure 2. The entire assembly shown in the figure is contained within a vacuum chamber, evacuated to $10^{-5}$ torr, refilled to 760 torr with ultra-high purity argon prior to heating, and maintained at this pressure throughout the experiment. For the measurement, a mass $\left(m_{T b}\right)$ of pure $\mathrm{Tb}$, initially at ambient temperature $\left(T_{a}\right)$, is introduced into a bath of pure Al liquid of known mass $\left(m_{A l}\right)$, with the system held isothermally at $T_{0}$ using an integrated thermocouple-based closed-loop control system. The resulting net thermal exchange between the calorimeter and the bath associated with isothermal control is given by

$$
\dot{q}_{c a l}=\dot{q}_{\text {heat }}+\dot{q}_{\text {melt }}+\dot{q}_{\text {mix }}+\dot{q}_{0}
$$

where the first three terms on the right-hand-side (RHS) are exchange fluxes associated with heating, melting, and mixing of the added material, respectively. The fourth term is the heat flux required to maintain isothermal conditions at $T_{0}$ in the bath, with no addition of material. Upon the addition of the terbium mass, $m_{T b}$, to the bath, the net exchange gives rise to a sensible thermal transient which is measured using a thermopile in contact with the melt crucible. An example thermal trace is shown in Figure 3. The measured temperature transient is related to the specimen-bath reaction enthalpy according to:

$$
\delta q_{\text {meas }}=\int_{0}^{\infty}\left(\dot{q}_{c a l}-\dot{q}_{0}\right) d t=\beta \int_{0}^{\infty}\left(T-T_{0}\right) d t,
$$

and we compute the incremental heat of mixing for this transient as

$$
\delta q_{\text {mix }}=\delta q_{\text {meas }}-\delta q_{\text {heat }}-\delta q_{\text {melt }}
$$

where

$$
\begin{gathered}
\delta q_{\text {heat }}=\frac{m_{T b}}{M_{T b}}\left(\int_{T_{a}}^{T_{\text {melt }}} c_{p}^{\text {sol }} d T+\int_{T_{\text {melt }}}^{T_{0}} c_{p}^{l i q} d T\right) \text { and } \\
\delta q_{\text {melt }}=\frac{m_{T b}}{M_{T b}}\left[H_{T b}^{l i q}\left(T_{\text {melt }}\right)-H_{T b}^{\text {sol }}\left(T_{\text {melt }}\right)\right] .
\end{gathered}
$$

Here, $M_{T b}$ and $m_{T b}$ denote the molar and total mass of the Tb specimen, respectively, and $\beta$ is the ISC calorimeter constant. The temperature dependent molar heat capacities $\left(c_{p}\right)$ were determined from SGTE free energy parameterizations [79].

The ISC calorimeter constant, $\beta$, was determined using pure $\mathrm{Al}$ solid specimens and a pure $\mathrm{Al}$ bath. In this case, $\delta q_{\text {mix }}=0$, and the left-hand side (LHS) of Equation (2) can computed from the heat capacity and enthalpy of melting for $\mathrm{Al}$, which are explicitly known. The right-hand side (RHS) of Equation (2) is determined from the measured temperature signal, permitting quantitative determination of $\beta$ for the specific temperature and mass of the bath, using Equations (3)-(5). Calibration measurements used to determine the calorimeter constant are summarized in Table 2, and the constant was determined as $-0.08336 \mathrm{~J} / \mathrm{sK}$ (The reported uncertainty of $\pm 5 \%$ for $\beta$ is based on 1.5 standard deviations, with respect to pure $\mathrm{Al}$ measurements, as described in Appendix A).

Immediately following the calibration measurement, $\Delta H_{\text {mix }}$ measurements were performed at $T_{0}=1364 \mathrm{~K}$ by introducing solid $\mathrm{Tb}\left(T_{a}=298 \mathrm{~K}\right)$ to the melt in incremental amounts of $1.8528 \mathrm{~g}$, $3.4288 \mathrm{~g}$, and $4.861 \mathrm{~g}$, yielding alloys with mole fractions of $\mathrm{Tb}\left(x_{T b}\right)$ of $0.030,0.054$, and 0.075, respectively. The results are summarized in Table 3. Incremental mixing enthalpy (relative to the previous state) is denoted as $\delta q_{\text {mix }}$ while the mixing enthalpy relative to the unmixed pure $\mathrm{Al}$ and $\mathrm{Tb}$ components is denoted as $\Delta H_{\text {mix }}$. Attempts to perform ISC measurements with higher $\mathrm{Tb}$ content resulted in non-negligible reaction with the $\mathrm{ZrO}_{2}$ calorimeter crucible, which interfered with the thermal transient signal. Measured quantities are shown in Table 3 for these cases, but no enthalpy of mixing is reported. 
Table 2. ISC calibration data.

\begin{tabular}{cc}
\hline Parameter & Value \\
\hline$T_{a}$ & $298 \mathrm{~K}$ \\
$T_{0}$ & $1364 \mathrm{~K}$ \\
$m_{A l}^{\text {crucible }}$ & $9.4869 \mathrm{~g}$ \\
$m_{A l}$ & $0.7009 \mathrm{~g}$ \\
$M_{A l}$ & $26.98 \mathrm{~g} / \mathrm{mol}$ \\
$M_{T b}$ & $158.93 \mathrm{~g} / \mathrm{mol}$ \\
$\delta q_{\text {heat }}$ & $826.05 \mathrm{~J}$ \\
$\delta q_{\text {melt }}$ & $278.26 \mathrm{~J}$ \\
$\delta q_{\text {meas }} / \beta$ & $-13,247.6 \mathrm{sK}$ \\
$\beta$ & $-0.08336 \pm 5 \% \mathrm{~J} / \mathrm{sK}$ \\
\hline
\end{tabular}

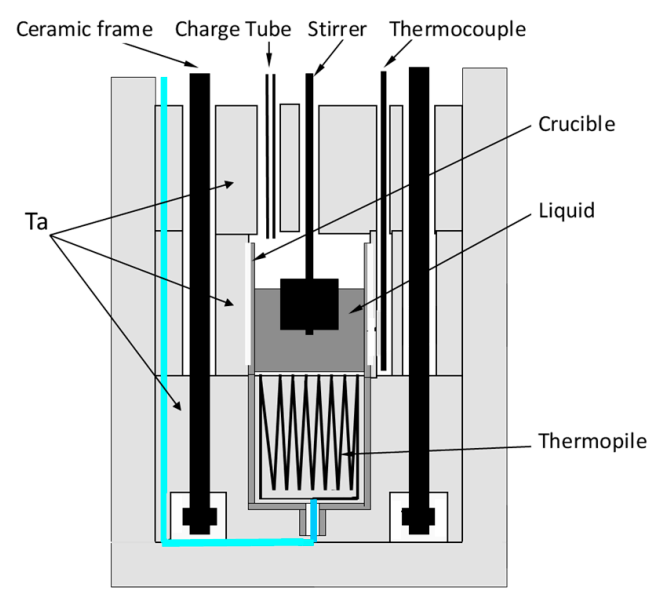

Figure 2. A schematic representation of the ISC, showing the essential calorimetry and specimen handling features (primary heating and vacuum systems not shown).

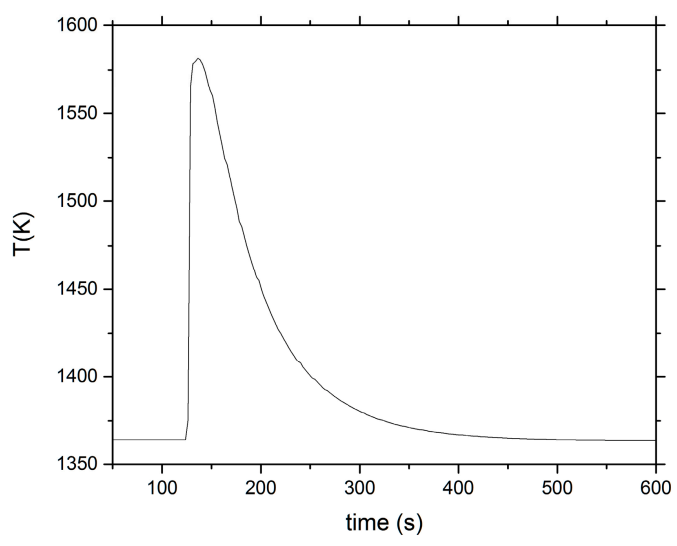

Figure 3. A typical ISC trace showing the thermal transient upon $\mathrm{Tb}$ specimen injection.

Table 3. Incremental ISC mixing enthalpy measurements for $T_{0}=1364 \mathrm{~K}$.

\begin{tabular}{cccccc}
\hline $\boldsymbol{m}_{\boldsymbol{A} \boldsymbol{l}}(\mathrm{g})$ & $\delta \boldsymbol{m}_{\boldsymbol{T b}}(\mathrm{g})$ & $\boldsymbol{m}_{\boldsymbol{T b}}(\mathrm{g})$ & $\boldsymbol{x}_{\boldsymbol{T b}}$ & $\delta \boldsymbol{q}_{\text {mix }}(\mathrm{J} / \mathbf{m o l})$ & $\Delta \boldsymbol{H}_{\text {mix }}(\mathrm{J} / \mathbf{m o l})$ \\
\hline 10.1878 & 1.8528 & 1.8528 & 0.03 & -4955.05 & -4955.05 \\
- & 1.5676 & 3.4288 & 0.05 & -3994.04 & -8949.09 \\
- & 1.4322 & 4.8610 & 0.08 & -2044.05 & $-10,993.1$ \\
10.85 & 6.4362 & 6.4362 & 0.09 & -1074.16 & - \\
- & 1.4510 & 7.8872 & 0.11 & -943.902 & - \\
\hline
\end{tabular}


For higher solute content, we turn to a container-less approach and employ electromagnetic levitation coupled with drop-calorimetry (EMLDC). The basic setup is shown in Figure 4. In this method, a stable levitation condition is established with a specimen of known mass under vacuum $\left(10^{-6}\right.$ Torr $)$ at a fixed temperature $\left(T_{\text {drop }}\right)$. Temperature is controlled by induction heating with forced gas (ultra-high purity $(99.999 \%) \mathrm{He}+5 \% \mathrm{H}_{2}$ gas, supplied by Matheson Company) $\left(\mathrm{He}+5 \% \mathrm{H}_{2}\right)$ and measured using a non-contact infrared pyrometer. After a stable condition is reached at $T_{d r o p}$, the coil is de-energized and the specimen falls by gravity into the calorimeter vessel. The calorimeter vessel is simply a solid copper cup with a conical bottom and a total mass of $167.0 \mathrm{~g}$. The specimen temperature at the time of contact with the calorimeter $\left(T_{c o n}\right)$ is computed by accounting for heat loss during the fall period (see Appendix B). The temperature transient in the calorimeter is measured using a thermocouple positioned just below the contact surface. A typical thermal trace is illustrated in Figure 5. The measured signal reflects rapid heat transfer from the specimen to the calorimeter upon contact and the evolution of heat during solidification and other phase changes. After the initial local heating, the measured signal reveals a slow cooling effect associated with heat redistribution within the calorimeter and heat loss from the calorimeter to its surroundings as it returns to temperature, $T_{0}$.

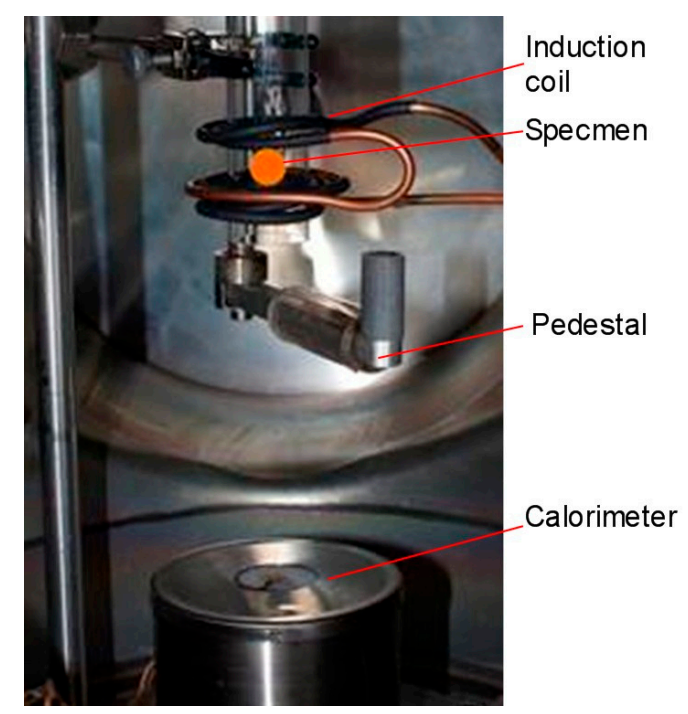

Figure 4. The levitation, heating, and calorimetry components of the EMLDC equipment.

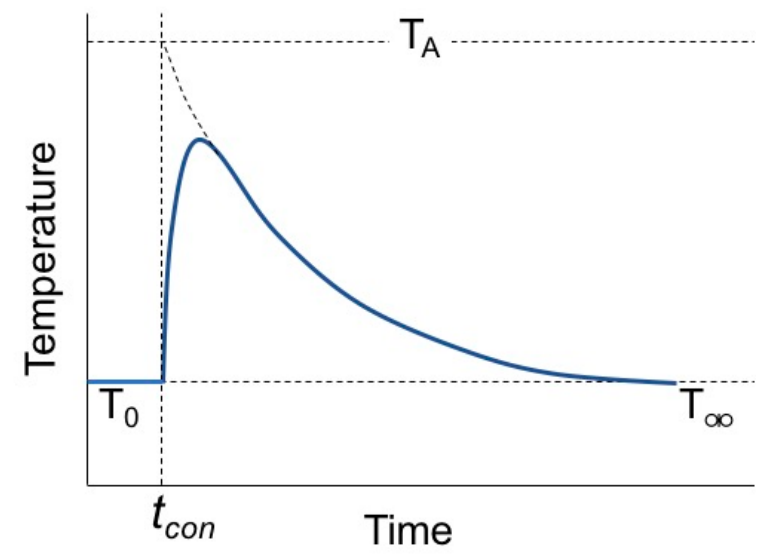

Figure 5. An example thermal trace, showing the characteristic temperatures (as listed in Table 4) for the EMLDC method. 
The measured thermal exchange in the calorimeter is generally given as

$$
\dot{q}_{c a l}=\dot{q}_{c o o l}+\dot{q}_{f r}+\dot{q}_{\text {trans }}+\dot{q}_{0}
$$

where the first three terms on the right-hand-side give contributions from the dropped specimen, including cooling, freezing, and any other solid-state phase transitions that may occur, respectively. The last term is associated with thermal equilibration of the calorimeter, involving heat transfer within the calorimeter itself and thermal exchange with the surroundings. The thermal transient measured in the calorimeter includes all of these contributions, so the specimen contribution is given by

$$
\delta q_{\text {spec }}=\delta q_{c a l}-\delta q_{0}=\phi \int_{0}^{\infty}\left(T-T_{0}\right) d t .
$$

The enthalpy of mixing in the liquid can be determined as

$$
q_{m i x}=\delta q_{s p e c}-n\left(\sum f_{p} \Delta H_{f}-\sum x_{i} \delta q_{i}^{T}\right),
$$

where $n$ is the total number of moles (of atoms) in the specimen, $\Delta H_{f}$ is the molar enthalpy of formation of a given phase at $298 \mathrm{~K}, f_{p}$ is the molar phase fraction of each phase, and the first term in parentheses is summed over all phases present in the quenched droplet. The second term in parentheses reflects the total molar enthalpy change for each elemental component, between the $298 \mathrm{~K}$ ground state and the liquid at $T_{c o n}$, and it is summed over all components ( $\mathrm{Al}$ and $\mathrm{Tb}$ in the present case), where $x_{i}$ is the mole fraction of each component. Explicitly:

$$
\delta q_{A l}^{T}=\int_{298}^{T_{m}} c_{p}^{A l, f c c} d T+\Delta H_{m}+\int_{T m}^{T_{c o n}} c_{p}^{A l, l i q} d T
$$

and

$$
\delta q_{T b}^{T}=\int_{298}^{T_{m}} c_{p}^{T b, \eta} d T+\Delta H_{m}+\int_{T_{m}}^{T_{c o n}} c_{p}^{T b, l i q} d T .
$$

Note that the expression in brackets in Equation (8) gives the total molar enthalpy difference between the quenched droplet at ambient temperature and the unmixed liquid at $T=T_{\text {con }}$. The required formation enthalpy (for $\mathrm{Al}_{3} \mathrm{~Tb}$ ) is computed using a DFT approach (see Appendix $\mathrm{C}$ ).

For our experiments, the time scale for the measured local calorimeter heating upon specimen contact is much shorter than the time scale for cooling back to ambient conditions. Accordingly, we model the heating as instantaneous and locally adiabatic followed by Newtonian cooling with a characteristic exponential decay. We note that conditions are not adiabatic, but we define a local adiabatic equivalent temperature, $T_{A}$, as the maximum temperature that would be reached in the limit of instantaneous adiabatic heating of a small local (i.e., effective) mass of the calorimeter upon specimen contact. The thermal transient measured upon contact with the non-adiabatic copper calorimeter is modeled as

$$
T_{0}+\left(T_{A}-T_{0}\right) \exp \left(-\frac{t}{\tau}\right)
$$

where $\tau$ is a calorimeter relaxation time, and $T_{A}$ is a local adiabatic equivalent temperature corresponding to the limit of rapid heat extraction from the specimen. This temperature is treated as a fit parameter, along with $\tau$. Equation (11) describes the measured behavior very closely, as shown by the root-mean-square-error (RMSE) values listed in Table 4, determined over the temperature range $T<T_{A}-0.25 \mathrm{~K}$. Once the values of $\tau$ and $T_{A}$ have been determined, the appropriate heat balance can be applied. Moreover, since $q_{c a l}=q_{\text {spec }}$ for this adiabatic heating, Equations (7)-(10) yield

$$
q_{\text {spec }}=-\phi \int_{T_{0}}^{T_{A}} c_{P}^{C u(s)} d T
$$


where the calorimeter constant, $\phi$, includes the effective calorimeter mass associated with non-uniform rapid heating upon contact, so that it includes the effects of specimen size and calorimeter size and shape.

The time-dependent heat transfer will be influenced by specimen size for a given calorimeter configuration (size, shape, insulation, thermocouple placement, etc.). Accordingly, determination of the calorimeter constant requires a standard specimen of the approximate size/mass of the specimen for which the enthalpy measurement is to be performed. In this work, two sets of calibration measurements were performed using pure $\mathrm{Al}$ specimens, with masses of $0.25 \mathrm{~g}$ and $0.5 \mathrm{~g}$, nominally. Calibration measurements are listed along with applicable alloy test measurements in Table 4. Underlined values of the calorimeter constant $(\phi)$ indicate an average of measured values determined from applicable calibration experiments listed. The stated specimen temperatures correspond to those shown in Figure 5. Pure Al specimens were used to determine $\phi$ for the two different nominal specimen sizes, where:

$$
\frac{M_{A l}}{m} q_{\text {meas }}=\int_{T_{h}}^{T_{m}} c_{P}^{A l(L)} d T+\Delta H_{m}+\int_{T_{m}}^{T_{A}} c_{P}^{A l(s)} d T
$$

where $m$ is the specimen mass. We note that Equation (13) can be recovered from Equations (7)-(9) for a pure $\mathrm{Al}$ specimen, since $q_{m i x}$ and $\Delta H_{f}$ both are equal to zero. Combining Equations (12) and (13), the calorimeter constant was determined using the pure $\mathrm{Al}$ samples, and the enthalpies of the alloy specimens were measured using the mean calorimeter constant determined from the calibration runs, as listed (type "cal") in Table 4 (standard relative uncertainty of $1.3 \%$; see Appendix A).

Table 4. Summary of EMLDC measurements for $\Delta H_{m i x}$ for Al-Tb liquid.

\begin{tabular}{|c|c|c|c|c|c|c|c|c|c|c|c|c|}
\hline$\#$ & Type & $x_{T b}$ & $\begin{array}{c}\text { Mass } \\
\text { (g) }\end{array}$ & $\begin{array}{c}T_{\text {drop }} \\
\text { (K) }\end{array}$ & $T_{c o n}$ & $\begin{array}{c}T_{0} \\
(\mathrm{~K})\end{array}$ & $\begin{array}{l}T_{A} \\
(\mathrm{~K})\end{array}$ & $\begin{array}{l}T_{\infty} \\
(\mathrm{K})\end{array}$ & $\begin{array}{c}\text { RMSE } \\
\text { (K) }\end{array}$ & $\begin{array}{c}q_{c a l} \\
(\mathrm{~J} / \mathrm{mol})\end{array}$ & $\phi$ & $\begin{array}{c}\Delta H_{m i x} \\
(\mathrm{~kJ} / \mathrm{mol})\end{array}$ \\
\hline 1 & $\mathrm{cal}$ & 0 & 0.5206 & 1245.0 & 1241.8 & 292.3 & 304.4 & 294.9 & 0.013 & 744.4 & 2.692 & - \\
\hline 2 & cal & 0 & 0.5159 & 1161.8 & 1159.1 & 298.0 & 309.0 & 294.7 & 0.004 & 684.9 & 2.710 & - \\
\hline 3 & $\mathrm{cal}$ & 0 & 0.5190 & 1176.3 & 1173.5 & 298.2 & 309.7 & 295.2 & 0.031 & 697.6 & 2.657 & - \\
\hline 4 & cal & 0 & 0.5133 & 1078.9 & 1076.5 & 295.9 & 306.2 & 294.6 & 0.042 & 632.7 & 2.693 & - \\
\hline 5 & $\mathrm{cal}$ & 0 & 0.5173 & 1303.7 & 1297.7 & 296.5 & 309.0 & 294.7 & 0.016 & 773.2 & 2.717 & - \\
\hline 6 & cal & 0 & 0.5168 & 1258.9 & 1255.7 & 298.1 & 310.1 & 295.3 & 0.001 & 744.7 & 2.718 & - \\
\hline 7 & meas & 0.1 & 0.4796 & 1292.0 & 1286.1 & 297.5 & 305.6 & 296.2 & 0.015 & 493.1 & 2.698 & -16.61 \\
\hline 8 & cal & 0 & 0.2476 & 1080.3 & 1076.5 & 292.9 & 298.1 & 293.2 & 0.001 & 307.5 & 2.570 & - \\
\hline 9 & cal & 0 & 0.2467 & 1245.6 & 1240.7 & 295.4 & 301.4 & 293.7 & 0.024 & 353.6 & 2.585 & - \\
\hline 10 & meas & 0.2 & 0.3476 & 1406.5 & 1394.7 & 294.6 & 300.4 & 294.0 & 0.004 & 343.2 & 2.578 & -27.08 \\
\hline 11 & meas & 0.2 & 0.3249 & 1439.5 & 1426.7 & 293.1 & 298.8 & 293.2 & 0.007 & 332.0 & 2.578 & -26.37 \\
\hline
\end{tabular}

The EMLDC method described above requires determination of the thermodynamic state of the quenched specimen. This requires knowledge of the phases present in the quenched droplet, their relative amounts, and their formation energies. Based on the equilibrium phase diagram, we expect the quenched droplets to be comprised of the $\mathrm{Al}(\mathrm{fcc})$ and $\mathrm{Al}_{3} \mathrm{~Tb}(\delta)$ phases and estimate the expected molar fraction of the $\delta$ phase as 0.4 and 0.8 for alloy compositions $\left(x_{T b}\right)$ of 0.1 and 0.2 , respectively. We verified these estimates experimentally using X-ray diffraction (XRD) and scanning electron microscopy, as shown in Figure 6 (SEM analysis was done using a JEOL JSM-5910LV instrument. XRD was performed with a PANalytical X-Pert Pro diffractometer). Based on the XRD patterns shown in Figure 6a, the phases present in the quenched droplets were identified as $\mathrm{Al}$ (fcc) and $\mathrm{Al}_{3} \mathrm{~Tb}(\delta)$ for both compositions $\left(x_{T b}=0.1,0.2\right)$. The corresponding microstructures are shown in Figure $6 \mathrm{~b}, \mathrm{c}$, revealing primary $\delta$ phase (light) and a two-phase (fcc $+\delta$ ) eutectic constituent (dark). To measure the fraction of primary $\delta$, quantitative image analysis was performed using two images ( $1280 \times 960$ pixels) for each composition, with pixel sizes of 0.1 and $0.2 \mathrm{~mm}$. Measurements yielding average $\delta$ fractions of 0.31 and 0.77 for $x_{T b}=0.1$ and 0.2 , respectively. Based on the eutectic composition 
of $x_{T b}=0.03$ (see Figure 1), the two-phase eutectic structure is expected to include $12 \% \delta$ and $88 \% \mathrm{Al}$ (fcc). Accordingly, the total molar fraction of the $\delta$ phase was determined to be 0.396 and $0.797 \%$ for $x_{T b}=0.1$ and 0.2 , respectively, in very good agreement with our original estimates of 0.4 and 0.8. Assuming that the formation energy at $0 \mathrm{~K}$ is equivalent to the formation enthalpy at $298 \mathrm{~K}$, we computed the required enthalpy of formation for $\mathrm{Al}_{3} \mathrm{~Tb}(\delta)$ from first principles, obtaining a value of $-43.2 \mathrm{~kJ} / \mathrm{mol}$ (see Appendix C), relative to the pure $\mathrm{Al}$ and $\mathrm{Tb}$ reference states at $0 \mathrm{~K}[53,80]$.

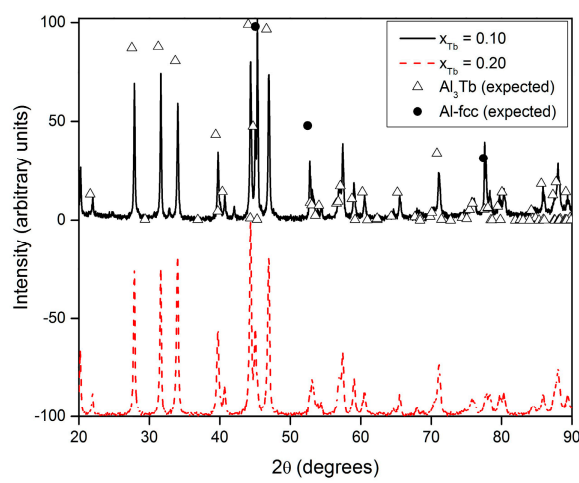

(a)

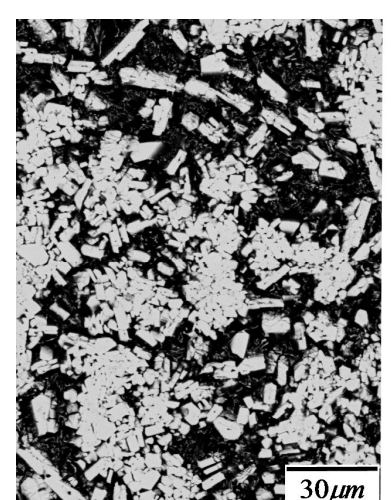

(b)

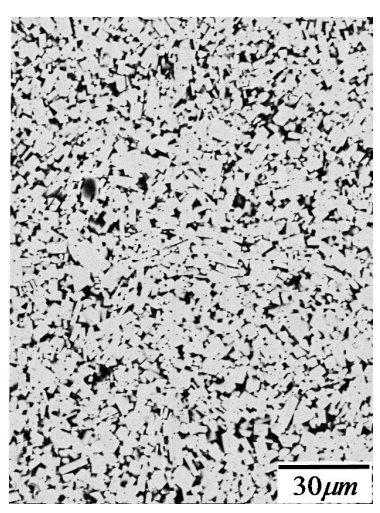

(c)

Figure 6. (a) XRD patterns indicating the fcc $+\delta$ constitution of the quenched alloys, with $f_{\delta}=0.4$ and 0.8 for $x_{T b}=0.1$ and 0.2 , respectively (XRD specimens: sectioned and diamond-polished to $0.6 \mu \mathrm{m}$ finish); (b,c) SEM images of EMLDC specimens showing the $\delta$ phase (light) and a two-phase eutectic constituent (dark) for alloy compositions of $x_{T b}=(\mathbf{b}) 0.1$ and (c) 0.2 (backscattered electron contrast, $20 \mathrm{kV}$ accelerating voltage, $10 \mathrm{~mm}$ working distance).

\section{Analysis and Discussion}

To establish additional thermodynamic context for our enthalpy of mixing measurements for the $\mathrm{Al}-\mathrm{Tb}$ liquid phase, we now consider appropriate models and specifically examine the application of three different semi-empirical treatments, all arising from the general model

$$
\Delta H_{\text {mix }}^{\mathrm{Liq}}=\frac{1}{1+2 y_{\mathrm{Al}_{2} \mathrm{~Tb}}}\left(\sum_{i}\left(\sum_{j>i} y_{i} y_{j} \sum_{k=0}^{n}{ }^{k} L_{i, j}^{\varphi}\right)+y_{\mathrm{Al}_{2} \mathrm{~Tb}} \Delta H_{f}^{\mathrm{Al}_{2} \mathrm{~Tb}}\right)
$$

where $x_{i}$ are the elemental mole fractions, and $y_{i}$ are mole fractions of associate species $\mathrm{Al}, \mathrm{Tb}$, and $\mathrm{Al}_{2} \mathrm{~Tb}$. The model parameters determined on the basis of our measurements are listed in Table 5. The resulting model descriptions of the mixing enthalpy are plotted in Figure 7 for $T=1364 \mathrm{~K}$ and compared with measured values. Corresponding model descriptions of chemical activity and partial molar mixing enthalpy $\left(\overline{\Delta H}_{\text {mix }}\right)$ are also plotted. In addition, the Miedema model prediction [76-78] is included in each figure for comparison.

It is significant to point out that the experimental data show very good agreement with the Miedema [76-78] prediction, which involves no adjustable parameters and serves as a baseline model. These figures also illustrate clearly that all three of the CALPHAD formulations (with the parameters listed in Table 5) provide similar descriptions of $\Delta H_{m i x}$ for this alloy over the dilute regime. Comparison of the modeled chemical activities suggests relatively small differences in the non-ideality for Al-rich compositions. This behavior is isolated more clearly in the partial molar mixing enthalpy, plotted in Figure 7c, which shows the different values of $\left(\overline{\Delta H}_{\text {mix }}\right)$ in the limit as $x_{T b} \rightarrow 0$. Generally, Figure 7 shows that multiple model formulations can provide reasonable descriptions of the measured behavior. Further discrimination will require experimental measurements in intermediate and $\mathrm{Tb}$-rich compositional regimes. Considering the challenges related to crucible reactions, this calls for additional container-less experiments. 
Table 5. Parameters for thermodynamic models of $\Delta H_{m i x}^{L i q}$.

\begin{tabular}{|c|c|c|c|c|c|}
\hline & Regular & Subregular & \multicolumn{3}{|c|}{ Associate } \\
\hline$i$ & $\mathrm{Al}$ & $\mathrm{Al}$ & $\mathrm{Al}$ & $\mathrm{Tb}$ & $\mathrm{Al}_{2} \mathrm{~Tb}$ \\
\hline j & $\mathrm{Tb}$ & $\mathrm{Tb}$ & $\mathrm{Tb}$ & $\mathrm{Al}_{2} \mathrm{~Tb}$ & $\mathrm{Al}$ \\
\hline${ }^{0} L_{i, j}(\mathrm{~J} / \mathrm{mol})$ & $-160,000$ & $-128,000+29.001 \mathrm{~T}$ & $-75,252$ & $-20,342$ & $-35,455$ \\
\hline${ }^{1} L_{i, j}(\mathrm{~J} / \mathrm{mol})$ & - & $-80,455+30.998 \mathrm{~T}$ & - & - & - \\
\hline${ }^{3} L_{i, j}(\mathrm{~J} / \mathrm{mol})$ & - & 30,342 & - & - & - \\
\hline$\Delta G_{A l_{2} T b}^{\circ / \mathrm{J}}(\mathrm{J} / \mathrm{mol})$ & - & - & \multicolumn{3}{|c|}{$-113,233+18.904 \mathrm{~T}$} \\
\hline Notes & \multicolumn{2}{|c|}{$\begin{array}{c}y_{i}=x_{i} \\
\left(y_{\mathrm{Al}_{2} \mathrm{~Tb}}=0\right)\end{array}$} & \multicolumn{3}{|c|}{$\begin{array}{c}\Delta G_{A l_{2} T b}^{\circ}=-R T \ln \left(\frac{a_{A l_{2} T b}}{a_{A l}^{2} \mathrm{a}_{\mathrm{Tb}}}\right) \\
2 \mathrm{Al}+\mathrm{Tb} \rightarrow \mathrm{Al}_{2} \mathrm{~Tb}\end{array}$} \\
\hline
\end{tabular}

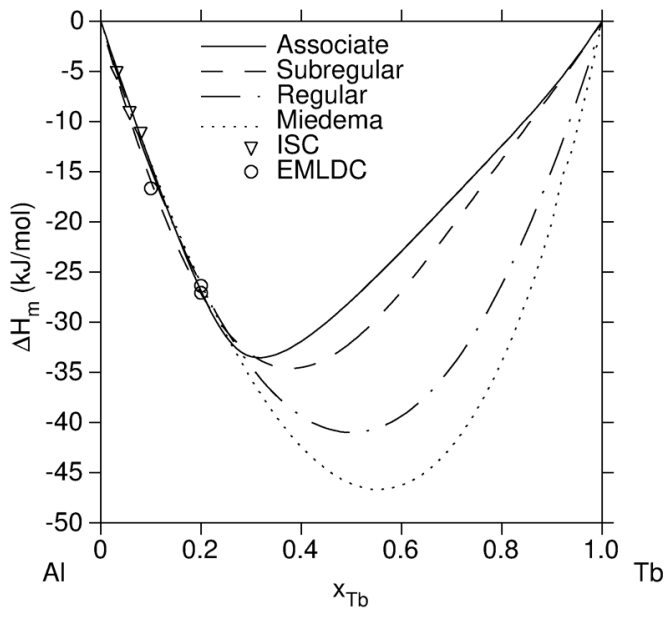

(a)

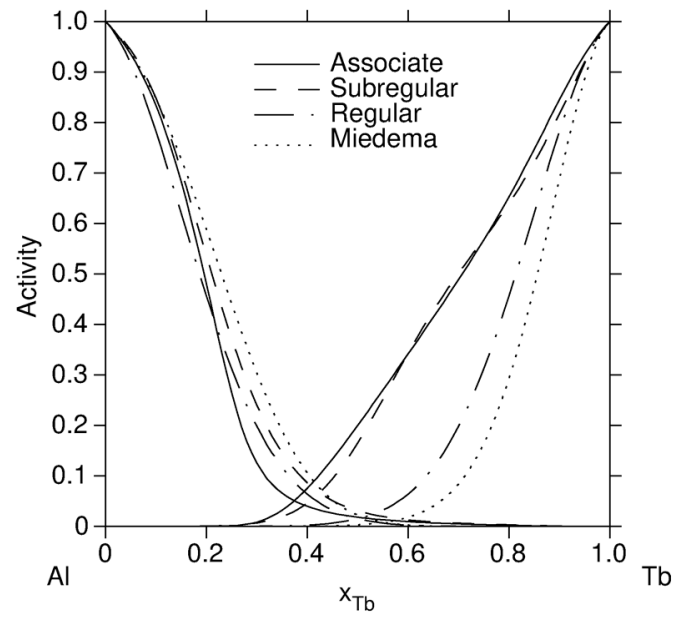

(b)

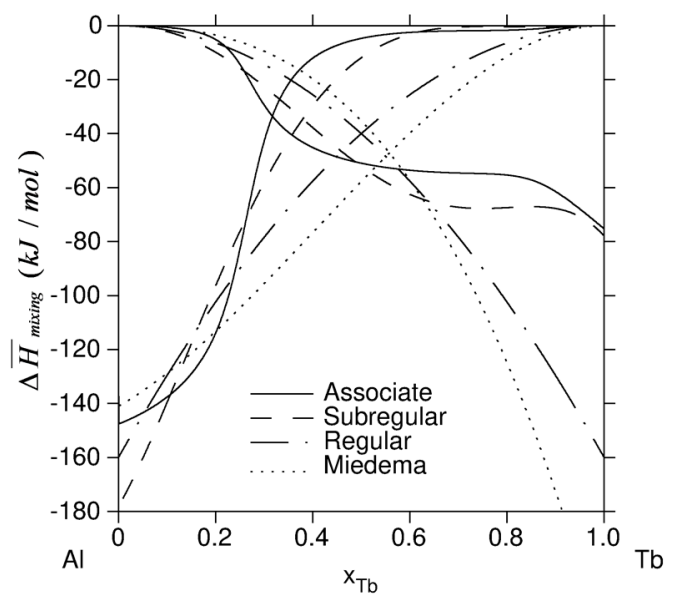

(c)

Figure 7. The liquid models: (a) mixing enthalpy with measured values; (b) chemical activity; and (c) partial molar enthalpy of mixing, calculated for $\mathrm{T}=1364 \mathrm{~K}$ (all referenced to pure $\mathrm{Al}$ and $\mathrm{Tb}$ liquid states).

\section{Conclusions}

We report here measurements of the enthalpy of mixing in the liquid phase for Al-Tb alloys, for $\mathrm{Tb}$ mole fractions up to $x_{\mathrm{T}}=0.2$. Specifically, we utilize isothermal solution calorimetry and isoperibolic electromagnetic levitation drop calorimetry to measure the enthalpy of mixing, employing 
X-ray diffraction, scanning electron microscopy, and first principles calculations to provide necessary quantification of the quenched states and component reference states. Based on our measurements, we offer three different assessed semi-empirical solution models for the excess free energy of the liquid, including regular, subregular, and associate model formulations for the enthalpy of mixing. All three of these model formulations provide very good representation of the measured behavior over the limited range examined. Our results highlight the need for additional measurements targeting the composition range of $0.5<x_{T b}<0.7$, which would enable further refinement of the general model.

Acknowledgments: This work was supported by the U.S. Department of Energy (DOE), Office of Science, Basic Energy Sciences, Materials Science and Engineering Division. The research was performed at the Ames Laboratory, which is operated for the U.S. DOE by Iowa State Univ. under contract No. DE-AC02-07CH11358.

Author Contributions: Shihuai Zhou designed the ISC experiments. Ralph Napolitano and Carl Tackes designed the EMLDC experiments. Shihuai Zhou and Carl Tackes performed the experiments; Shihuai Zhou and Ralph Napolitano analyzed the data. Ralph Napolitano and Shihuai Zhou wrote the paper. All authors have read and approved the final manuscript.

Conflicts of Interest: The authors declare no conflict of interest.

\section{Appendix A}

The uncertainties for the calibration constants, $\beta$ and $\phi$ for ISC and EMLDC, respectively, were determined through a series of measurements using pure aluminum (0.9999) standards. For ISC, the measurements were performed with the specimen under argon at atmospheric pressure and a constant temperature of $1411 \mathrm{~K}$. By successive incremental additions of aluminum (at ambient temperature, $298 \mathrm{~K})$ in small amounts $(\sim 0.5 \mathrm{~g})$ to a liquid $\mathrm{Al}$ bath held in an $\mathrm{Al}_{2} \mathrm{O}_{3}$ crucible, ISC measurements of the thermal transient yielded a series of independent measurements of $\beta$, with a relative standard deviation of $3.4 \%$, shown in Table A1. Similarly, a set of six measurements were performed to determine the EMLDC calibration constant $(\phi)$, using pure aluminum specimens, nominally $0.5 \mathrm{~g}$ each (also shown in Table 5). The relative standard deviation was determined to be $0.85 \%$, as shown in Table A1. Based on these measurements and taking the standard uncertainties as 1.5 standard deviations as measured in the calibration experiments, we estimate the standard uncertainties for the ISC and EMLDC methods as 5\% and 1.3\%, respectively.

Table A1. Summary of experiments for determination of the standard uncertainty for ISC and EMLDC.

\begin{tabular}{ccccc}
\hline & ISC & & \multicolumn{2}{c}{ EMLDC } \\
\hline $\begin{array}{c}\text { Incremental Mass, Al } \\
\mathbf{( g )}\end{array}$ & $\begin{array}{c}\text { Cumulative Mass, Al } \\
(\mathbf{g})\end{array}$ & $\begin{array}{c}\text { Calibration Const. } \\
(\boldsymbol{\beta})\end{array}$ & $\begin{array}{c}\text { Total Mass, Al } \\
\mathbf{( g )}\end{array}$ & $\begin{array}{c}\text { Calibration Const. } \\
(\boldsymbol{\phi})\end{array}$ \\
\hline- & 0.10152 & -0.33261 & 0.5206 & 2.692 \\
0.06331 & 0.16483 & -0.32971 & 0.5159 & 2.710 \\
0.04129 & 0.20612 & -0.31686 & 0.5190 & 2.657 \\
0.04251 & 0.24863 & -0.30591 & 0.5133 & 2.693 \\
0.06162 & 0.31025 & -0.32572 & 0.5173 & 2.717 \\
- & - & - & 0.5168 & 2.718 \\
\hline Mean & - & -0.32216 & - & 2.698 \\
Standard Deviation (SD) & - & 0.01085 & - & 0.023 \\
SD (relative) & - & $3.4 \%$ & - & $0.85 \%$ \\
Relative Uncert. (1.5 SD) & - & $5.0 \%$ & - & $1.3 \%$ \\
\hline
\end{tabular}

\section{Appendix B}

For the EMLDC method, specimen cooling during the drop period was computed to determine the specimen temperature upon contact with the calorimeter:

$$
T_{\text {con }}=T_{\text {drop }}-\Delta T_{\text {drop }}=T_{\text {drop }}-\Delta T_{C}-\Delta T_{R}
$$


where $\Delta T_{C}$ and $\Delta T_{R}$ describe convective and radiative cooling during freefall. Using the parameters defined in Table A2, these were computed, respectively, as

$$
\begin{gathered}
\Delta T_{C}=B_{0} h\left(T_{\text {drop }}-T_{0}\right) \text { and } \\
\Delta T_{R}=B_{0} \sigma \varepsilon\left(T_{A}^{4}-T_{0}^{4}\right),
\end{gathered}
$$

where for the spherical drop:

$$
\begin{gathered}
B_{0}=A_{s} t_{f} W / m c_{P} \\
A_{S}=\left(36 \pi V^{2}\right)^{1 / 3} \\
t_{f}=\sqrt{2 z / g} \\
h=\frac{k}{D}\left[2+\left(0.4 R e^{1 / 2}+0.6 \operatorname{Re}^{2 / 3}\right) \operatorname{Pr}^{2 / 5}\right],
\end{gathered}
$$

and the Prandtl and Reynolds numbers were taken, respectively, as

$$
\begin{gathered}
\operatorname{Pr}=\mu c_{P} / k \\
R e=\rho V_{\infty} D / \mu .
\end{gathered}
$$

Table A2. Parameters used in the calculation of $T_{\text {con }}$.

\begin{tabular}{ccc}
\hline Parameter & Description & Units \\
\hline$\sigma$ & Stephan-Boltzmann constant (taken here as $5.67 \times 10^{-8}$ ) & $\mathrm{J} / \mathrm{m}^{2} \mathrm{sK}^{4}$ \\
$\varepsilon$ & Total hemispherical emissivity (taken here as 0.084$)$ & - \\
$c_{P}$ & Specimen heat capacity & $\mathrm{J} / \mathrm{mol}$ \\
$m$ & Mass of specimen & $\mathrm{g}$ \\
$W$ & Specimen molar mass & $\mathrm{g} / \mathrm{mol}$ \\
$A_{S}$ & Surface area of specimen & $\mathrm{m}^{2}$ \\
$V$ & Volume of specimen & $\mathrm{m}^{3}$ \\
$t_{f}$ & Fall duration & $\mathrm{s}$ \\
$h$ & Heat transfer coefficient & $\mathrm{W} / \mathrm{m}^{2} \mathrm{~K}$ \\
$\mu$ & Dynamic viscosity (gas) (taken here as $1.90 \times 10^{-5}$ ) & $\mathrm{Ns} / \mathrm{m}^{2}$ \\
$k$ & Thermal conductivity (gas) (taken here as 0.1513$)$ & $\mathrm{W} / \mathrm{mK}^{2}$ \\
$D$ & Specimen diameter & $\mathrm{m}$ \\
$V_{\infty}$ & Fluid velocity (taken as the average fall velocity) & $\mathrm{m} / \mathrm{s}$ \\
$\rho$ & Specimen density & $\mathrm{Kg} / \mathrm{m}^{3}$ \\
\hline
\end{tabular}

\section{Appendix C}

The total energy $\mathrm{E}^{\theta}$ is computed for each phase using the Vienna ab initio simulation package (VASP) [81-83] employing projector augmented wave method [83,84] and Perdew-Burke-Ernzerhof generalized gradient approximation (PBE-GGA) [85]. The "high precision" choice to ensure that the computed absolute energies were converged to a few meV. The spin-polarized electronic-structure calculations were enabled and the Monkhost $24 \times 24 \times 20$ "k-points" were employed for high precision. For each compound, the cell was fully relaxed with respect to distortion and dilatation, and it was confirmed the crystal structure was maintained. The enthalpy of formation for the a given compound is calculated as the difference between the energy $\mathrm{E}^{\theta}$ of the compound and the linear combination of the pure element reference state energies, $E_{A l}^{f c c}$ and $E_{T b}^{h c p}$, so that $\Delta H_{f}^{\theta}$ can be calculated as $\Delta H_{f}^{\theta}=E^{0}-x_{A l} E_{A l}^{f c c}-x_{T b} E_{T b}^{h c p}$. 


\section{References}

1. Xing, L.Q.; Hufnagel, T.C.; Eckert, J.; Loser, W.; Schultz, L. Relation between short-range order and crystallization behavior in Zr-based amorphous alloys. Appl. Phys. Lett. 2000, 77, 1970-1972. [CrossRef]

2. Chen, G.L.; Hui, X.D.; He, G.; Bian, Z. Multicomponent chemical short range order, undercooling, and the formation of bulk metallic glasses. Mater. Trans. 2001, 42, 1095-1102. [CrossRef]

3. Chen, G.L.; Hui, X.D.; Fan, S.W.; Kou, H.C.; Yao, K.F. Concept of chemical short range order domain and the glass forming ability in multicomponent liquid. Intermetallics 2002, 10, 1221-1232. [CrossRef]

4. Jakse, N.; Pasturel, A. Glass forming ability and short-range order in a binary bulk metallic glass by ab initio molecular dynamics. Appl. Phys. Lett. 2008, 93, 113104. [CrossRef]

5. Hao, S.G.; Kramer, M.J.; Wang, C.Z.; Ho, K.M.; Nandi, S.; Kreyssig, A.; Goldman, A.I.; Wessels, V.; Sahu, K.K.; Kelton, K.F.; et al. Experimental and Ab initio structural studies of liquid Zr ${ }_{2}$ Ni. Phys. Rev. B 2009, 79, 104206. [CrossRef]

6. Huang, L.; Wang, C.Z.; Hao, S.G.; Kramer, M.J.; Ho, K.M. Short-and medium-range order in amorphous $\mathrm{Zr}_{2} \mathrm{Ni}$ metallic alloy. Phys. Rev. B 2010, 81, 094118. [CrossRef]

7. Fang, X.W.; Wang, C.Z.; Yao, Y.X.; Ding, Z.J.; Ho, K.M. Signature of $\mathrm{Al}_{11} \mathrm{Sm}_{3}$ fragments in undercooled $\mathrm{Al}_{90} \mathrm{Sm}_{10}$ liquid from ab initio molecular dynamics simulations. J. Phys. Condens. Matter 2011, 23, 235104. [CrossRef] [PubMed]

8. Zhao, Y.F.; Lin, D.Y.; Chen, X.H.; Liu, Z.K.; Hui, X.D. Sluggish mobility and strong icosahedral ordering in Mg-Zn-Ca liquid and glassy alloys. Acta Mater. 2014, 67, 266-277. [CrossRef]

9. Zhang, F.; Sun, Y.; Ye, Z.; Zhang, Y.; Wang, C.-Z.; Mendelev, M.I.; Ott, R.T.; Kramer, M.J.; Ding, Z.-J.; Ho, K.-M. Solute-solute correlations responsible for the prepeak in structure factors of undercooled Al-rich liquids: A molecular dynamics study. J. Phys. Condens. Matter 2015, 27, 205701. [CrossRef] [PubMed]

10. Sterkhova, I.; Lad'yanov, V.; Kamaeva, L.; Umnova, N.; Umnov, P. On the tendency of the Co-, Ni-, and Fe-based melts to the bulk amorphization. Metall. Mater. Trans. A 2016, 47, 5487-5495. [CrossRef]

11. Zhu, A.W.; Shiflet, G.J.; Miracle, D.B. Glass forming ranges of Al-rare earth metal alloys: Thermodynamic and kinetic analysis. Scr. Mater. 2004, 50, 987-991. [CrossRef]

12. Iwamatsu, M.; Lai, S.K. Lowest-energy structures of 13-atom binary clusters: Do icosahedral clusters exist in binary liquid alloys? J. Non Cryst. Solids 2007, 353, 3698-3703. [CrossRef]

13. Zhu, A.W.; Shiflet, G.J.; Poon, S.J. Atomic bond deficiency as a structural defect in amorphous metals: Relevance to glass transitions. Acta Mater. 2008, 56, 593-601. [CrossRef]

14. Tian, H.; Zhang, C.; Wang, L.; Zhao, J.J.; Dong, C.; Wen, B.; Wang, Q. Ab initio molecular dynamics simulation of binary $\mathrm{Cu}_{64} \mathrm{Zr}_{36}$ bulk metallic glass: Validation of the cluster-plus-glue-atom model. J. Appl. Phys. 2011, 109, 123520. [CrossRef]

15. Tian, H.; Liu, H.; Zhang, C.; Zhao, J.J.; Dong, C.; Wen, B. Ab initio molecular dynamics simulation of binary $\mathrm{Ni}_{62.5} \mathrm{Nb}_{37.5}$ bulk metallic glass: Validation of the cluster-plus-glue-atom model. J. Mater. Sci. 2012, 47, 7628-7634. [CrossRef]

16. Hao, S.G.; Wang, C.Z.; Li, M.Z.; Napolitano, R.E.; Mendelev, M.I.; Ho, K.M. Prediction of cooling rate dependent ordering in metallic glass transition using a two-state model. Comput. Mater. Sci. 2010, 49, 615-618. [CrossRef]

17. Hao, S.G.; Wang, C.Z.; Li, M.Z.; Napolitano, R.E.; Ho, K.M. Dynamic arrest and glass formation induced by self-aggregation of icosahedral clusters in $\mathrm{Zr}_{1-\mathrm{x}} \mathrm{Cu}_{\mathrm{x}}$ alloys. Phys. Rev. B 2011, 84, 064203. [CrossRef]

18. Guo, J.Q.; Ohtera, K.; Kita, K.; Nagahora, J.; Kazama, N.S. Crystallization behavior of $\mathrm{Al}_{100-x} \mathrm{Sm}_{\mathrm{x}}$ $(\mathrm{x}=8-14$ at $\%)$ amorphous-alloys. Mater. Lett. 1995, 24, 133-138. [CrossRef]

19. Inoue, A. Amorphous, nanoquasicrystalline and nanocrystalline alloys in Al-based systems. Prog. Mater. Sci. 1998, 43, 365-520. [CrossRef]

20. Rizzi, P.; Antonione, C.; Baricco, M.; Battezzati, L.; Armelao, L.; Tondello, E.; Fabrizio, M.; Daolio, S. Crystals and nanocrystals in rapidly solidified Al-Sm alloys. Nanostruct. Mater. 1998, 10, 767-776. [CrossRef]

21. Wilde, G.; Sieber, H.; Perepezko, J.H. Glass formation versus nanocrystallization in an $\mathrm{Al}_{92} \mathrm{Sm}_{8}$ alloy. Scr. Mater. 1999, 40, 779-783. [CrossRef]

22. Wilde, G.; Sieber, H.; Perepezko, J.H. Glass formation in Al-rich Al-Sm alloys during solid state processing at ambient temperature. J. Non Cryst. Solids 1999, 252, 621-625. [CrossRef] 
23. Tjong, S.C.; Wang, J.Q. Microstructure and devitrification behavior of melt-spun Al-rich metallic glasses and nanostructured composites. Z. Metallkunde 2001, 92, 610-616.

24. Perepezko, J.H.; Hebert, R.J.; Wu, R.I.; Wilde, G. Primary crystallization in amorphous Al-based alloys. J. Non Cryst. Solids 2003, 317, 52-61. [CrossRef]

25. Kalay, Y.E.; Chumbley, L.S.; Kramer, M.J.; Anderson, I.E. Local structure in marginal glass forming Al-Sm alloy. Intermetallics 2010, 18, 1676-1682. [CrossRef]

26. Kalay, Y.E.; Yeager, C.; Chumbley, L.S.; Kramer, M.J.; Anderson, I.E. Initial crystallization in a nanostructured Al-Sm rare earth alloy. J. Non Cryst. Solids 2010, 356, 1416-1424. [CrossRef]

27. Zhang, F.; McBrearty, I.; Ott, R.T.; Park, E.; Mendelev, M.I.; Kramer, M.J.; Wang, C.Z.; Ho, K.M. Discovery of a meta-stable Al-Sm phase with unknown stoichiometry using a genetic algorithm. Scr. Mater. 2014, 81, 32-35. [CrossRef]

28. Ye, Z.; Zhang, F.; Sun, Y.; Mendelev, M.I.; Ott, R.T.; Park, E.; Besser, M.F.; Kramer, M.J.; Ding, Z.; Wang, C.Z.; et al. Discovery of a metastable $\mathrm{Al}_{20} \mathrm{Sm}_{4}$ phase. Appl. Phys. Lett. 2015, 106, 101903. [CrossRef]

29. Bokas, G.B.; Zhao, L.; Perepezko, J.H.; Szlufarska, I. On the role of Sm in solidification of Al-Sm metallic glasses. Scr. Mater. 2016, 124, 99-102. [CrossRef]

30. Sanders, W.S.; Warner, J.S.; Miracle, D.B. Stability of Al-rich glasses in the Al-La-Ni system. Intermetallics 2006, 14, 348-351. [CrossRef]

31. Hackenberg, R.E.; Gao, M.C.; Kaufman, L.; Shiflet, G.J. Thermodynamics and phase equilibria of the Al-Fe-Gd metallic glass-forming system. Acta Mater. 2004, 52, 3745. [CrossRef]

32. Wang, W.; Tang, Z.L.; Zhan, C.Y.; Nie, Z.R. Calculations of formation enthalpies of Al-Re intermetallics. Rare Met. Mater. Eng. 2009, 38, 2100-2105.

33. Wang, H.Y.; Gao, X.Y.; Zeng, J.M.; Ren, H.P.; Zhao, Y.J. First-principles of phase stability and solubility of Al-Re (La, Y) alloy. Rare Met. Mater. Eng. 2017, 46, 735-739.

34. Wu, R.I.; Wilde, G.; Perepezko, J.H. Glass formation and primary nanocrystallization in Al-base metallic glasses. Mater. Sci. Eng. A 2001, 301, 12-17. [CrossRef]

35. Sun, S.P.; Yi, D.Q.; Liu, H.Q.; Zang, B.; Jiang, Y. Calculation of glass forming ranges in Al-Ni-Re (Ce, La, Y) ternary alloys and their sub-binaries based on Miedema's model. J. Alloys Compd. 2010, 506, 377-387. [CrossRef]

36. Zhu, A.W.; Poon, S.J.; Shiflet, G.J. On glass formability of Al-Gd-Ni (Fe). Scr. Mater. 2004, 50, 1451-1455. [CrossRef]

37. Csontos, A.A.; Shiflet, G.J. Formation and chemistry of nanocrystalline phases formed during deformation in aluminum-rich metallic glasses. Nanostruct. Mater. 1997, 9, 281-289. [CrossRef]

38. Baricco, M.; Gaertner, F.; Cacciamani, G.; Rizzi, P.; Battezzati, L.; Greer, A.L. Thermodynamics of homogeneous crystal nucleation in Al-Re metallic glasses. Mater. Sci. Forum 1998, 269, 553-558. [CrossRef]

39. Boucharat, N.; Rosner, H.; Perepezko, J.H.; Wilde, G. Devitrification of Al-based glass forming alloys. Mater. Sci. Eng. A 2004, 375, 713-717. [CrossRef]

40. Jia, Y.B.; Song, H.F.; Chao, Q.; Wang, Q.; Dong, Y.D. Glass-forming ability and thermal stability of (Ce-La)-Ni-Al bulk amorphous alloys. Rare Metal Mater. Eng. 2010, 39, 997-1001.

41. Antonowicz, J. Atomic packing and phase separation in Al-rare earth metallic glasses. J. Mater. Sci. 2010, 45, 5040-5044. [CrossRef]

42. Li, R.; Stoica, M.; Wang, G.; Park, J.M.; Li, Y.; Zhang, T.; Eckert, J. Glass formation, thermal properties, and elastic constants of La-Al-Co alloys. J. Mater. Res. 2010, 25, 1398-1404. [CrossRef]

43. Chen, Z.; Angell, C.A.; Richert, R. On the dynamics of liquids in their viscous regime approaching the glass transition. Eur. Phys. J. E 2012, 35, 1-7. [CrossRef] [PubMed]

44. Angell, C.A. The viscous-liquid-glassy-solid problem. Acs. Sym. Ser. 1997, 676, 14-26.

45. Angell, C.A. Entropy and fragility in supercooling liquids. J. Res. Natl. Inst. Stand. Technol. 1997, 102, 171-185. [CrossRef] [PubMed]

46. Gschneidner, K.A., Jr.; Calderwood, F.W. The Al-Re (aluminum-rare earth) systems. Bull. Alloy Phase Diagr. 1988, 9, 658-668. [CrossRef]

47. Benigni, P.; Hassam, S.; Decreton, A.; Mikaelian, G.; Gajavalli, K.; Barrachin, M.; Fischer, E.; Rogez, J. Enthalpy of mixing in the Ag-Cd-In ternary liquid phase. J. Chem. Thermodyn. 2017, 107, 207-215. [CrossRef]

48. Debski, A.; Gasior, W. Calorimetric measurements of the Li-Zn system. Direct reaction method and mixing enthalpy. J. Chem. Thermodyn. 2016, 98, 111-117. [CrossRef] 
49. Nusperling, E.M.; Thiedemann, U.; Schaefers, K.; Qin, J.; Rosner-Kuhn, M.; Frohberg, M.G. Mixing enthalpy measurements of liquid $\mathrm{Fe}-\mathrm{Nb}-\mathrm{V}$ alloys by levitation alloying calorimetry. Rev. Metall. 1997, 94, $219-226$.

50. Naguet, C.; Azzaoui, M.; Fionari, J.M.; Vassiliev, V.; Hertz, J.; Bourkba, A.; Bouirden, L. Semi-experimental mixing enthalpy of ternary liquid phases as a support of phase-diagrams calculation. J. Chim. Phys. 1997, 94, 1026-1035. [CrossRef]

51. Zhou, S.; Napolitano, R.E. Phase equilibria and thermodynamic limits for partitionless crystallization in the Al-La binary system. Acta Mater. 2006, 54, 831-840. [CrossRef]

52. Jin, L.L.; Kang, Y.B.; Chartrand, P.; Fuerst, C.D. Thermodynamic evaluation and optimization of Al-La, Al-Ce, Al-Pr, Al-Nd and Al-Sm systems using the modified quasichemical model for liquids. Calphad 2011, 35, 30-41. [CrossRef]

53. Gao, M.C.; Rollett, A.D.; Widom, M. Lattice stability of aluminum-rare earth binary systems: A first-principles approach. Phys. Rev. B 2007, 75, 174120. [CrossRef]

54. Yang, Q.; Liu, X.; Bu, F.; Meng, F.; Zheng, T.; Zhang, D.; Meng, J. First-principles phase stability and elastic properties of Al-La binary system intermetallic compounds. Intermetallics 2015, 60, 92-97. [CrossRef]

55. Esin, Y.O.; Kolesnikov, S.P.; Baev, V.M.; Petrushevskii, M.S.; Geld, P.V. Formation enthalpies of liquid binary-alloys of aluminum and tin with lanthanum. Zhurnal Fizicheskoi Khimii 1981, 55, 1587-1588.

56. Sommer, F.; Keita, M.; Krull, H.G.; Predel, B.; Lee, J.J. Thermodynamic investigations of Al-La alloys. J. Less Common Met. 1988, 137, 267-275. [CrossRef]

57. Borzone, G.; Cardinale, A.M.; Parodi, N.; Cacciamani, G. Aluminum compounds of the rare earths: Enthalpies of formation of $\mathrm{Yb}-\mathrm{Al}$ and La-Al alloys. J. Alloys Compd. 1997, 247, 141-147. [CrossRef]

58. Gao, M.C.; Unlu, N.; Shiflet, G.J.; Mihalkovic, M.; Widom, M. Reassessment of Al-Ce and Al-Nd binary systems supported by critical experiments and first-principles energy calculations. Met. Mater. Trans. A 2005, 36, 3269-3279. [CrossRef]

59. Kang, Y.B.; Pelton, A.D.; Chartrand, P.; Fuerst, C.D. Critical evaluation and thermodynamic optimization of the Al-Ce, Al-Y, Al-Sc and Mg-Sc binary systems. Calphad 2008, 32, 413-422. [CrossRef]

60. Ivanov, M.I.; Berezutskii, V.V.; Shevchenko, M.A.; Kudin, V.G.; Sudavtsova, V.S. Thermodynamic properties of binary Al-Ce and Ce-Fe alloys. Powder Metall. Met. Ceram. 2015, 54, 80-92. [CrossRef]

61. Esin, Y.O.; Ryss, G.M.; Geld, P.V. Enthalpies of the formation of liquid alloys of cerium with aluminum. Zhurnal Fizicheskoi Khimii 1979, 53, 2380-2381.

62. Kober, V.I.; Lebedev, V.A.; Nichkov, I.F.; Raspopin, S.P.; Yamshchi, L.F. Thermodynamic properties of aluminum-rich Ce-Al alloys. Russ. Metall. 1973, 2, 163-166.

63. Shevchenko, M.O.; Berezutskii, V.V.; Ivanov, M.I.; Sudavtsova, V.S. Thermodynamic properties of binary Al-Pr alloys. Powder Metall. Met. Ceram. 2016, 55, 78-90. [CrossRef]

64. Zviadadze, G.N.; Chkhikvadze, L.A.; Kereselidze, M.V. Thermodynamic properties of binary melts of some rare earth metals with aluminum. Soobshch. Akad. Nauk. Gruz. SSR 1976, 81, 149-152.

65. Zhou, S.H.; Wang, Y.; Chen, L.Q.; Liu, Z.K.; Napolitano, R.E. Solution-based thermodynamic modeling of the Ni-Ta and Ni-Mo-Ta systems using first-principle calculations. Calphad 2009, 33, 631-641. [CrossRef]

66. Zhou, S.H.; Napolitano, R.E. Modeling of thermodynamic properties and phase equilibria for the Al-Sm binary system. Met. Mater.Trans. A 2008, 39, 502-512. [CrossRef]

67. Shevchenko, M.O.; Berezutski, V.V.; Ivanov, M.I.; Kudin, V.G.; Sudavtsova, V.S. Thermodynamic properties of alloys of the binary Al-Sm, Sm-Sn and ternary Al-Sm-Sn systems. J. Phase Equilib. Diffus. 2015, 36, 39-52. [CrossRef]

68. Bo, H.; Liu, L.B.; Hu, J.L.; Zhang, X.D.; Jin, Z.P. Thermodynamic re-assessment of the Al-Gd and Gd-Zr systems. Thermochim. Acta 2014, 591, 51-56. [CrossRef]

69. Jin, L.; Kang, Y.B.; Chartrand, P.; Fuerst, C.D. Thermodynamic evaluation and optimization of Al-Gd, Al-Tb, Al-Dy, Al-Ho and Al-Er systems using a modified quasichemical model for the liquid. Calphad 2010, 34, 456-466. [CrossRef]

70. Grobner, J.; Kevorkov, D.; Schmid-Fetzer, R. Thermodynamic calculation of Al-Gd and Al-Gd-Mg phase equilibria checked by key experiments. Z. Metallkunde 2001, 92, 22-27.

71. Kanibolotsky, D.S.; Golovataya, N.V.; Lisnyak, V.V. Calorimetric study of liquid gadolinium-based alloys. J. Therm. Anal. Calorim. 2004, 76, 323-327. [CrossRef]

72. Kanibolotsky, D.S.; Golovataya, N.V.; Bieloborodova, O.A.; Lisnyak, V.V. Calorimetric investigation of liquid Al-Ga-Gd alloys. Thermochim. Acta 2004, 421, 111-115. [CrossRef] 
73. Bo, H.; Liu, L.B.; Xiong, X.; Jin, Z.P. Thermodynamic assessment of the Al-Dy, Dy-Zr and Al-Dy-Zr systems. Chin. Sci. Bull. 2014, 59, 1738-1746. [CrossRef]

74. Meng, F.G.; Zhang, L.G.; Liu, H.S.; Liu, L.B.; Jin, Z.P. Thermodynamic optimization of the Al-Yb binary system. J. Alloys Compd. 2008, 452, 279-282. [CrossRef]

75. Sommer, F. Association model for the description of thermodynamic functions of liquid alloys II.-Numerical treatment and results. Z. Metallkunde 1982, 73, 77-86.

76. Miedema, A.R. A simple model for alloys: I. Rules for the alloying behaviour of transition metals. Philips Tech. Rev. 1973, 33, 149-160.

77. Miedema, A.R. A simple model for alloys: II. The influence of ionicity on the stability and other physical properties of alloys. Philips Tech. Rev. 1973, 33, 196-202.

78. Zhang, R.F.; Zhang, S.H.; He, Z.J.; Jing, J.; Sheng, S.H. Miedema calculator: A thermodynamic platform for predicting formation enthalpies of alloys within framework of Miedema's theory. Comput. Phys. Commun. 2016, 209, 58-69. [CrossRef]

79. Dinsdale, A.T. SGTE data for pure elements. Calphad 1991, 4, 317-425. [CrossRef]

80. Colinet, C.; Pastural, A.; Buschow, K.H.J. Molar enthalpies of formation of $\mathrm{LnAl}_{2}$ compounds. J. Chem. Thermodyn. 1985, 17, 1133-1139. [CrossRef]

81. Kresse, G.; Furthmüller, J. Efficient iterative schemes for ab initio total-energy calculations using a plane-wave basis set. Phys. Rev. B 1996, 54, 11169-11186. [CrossRef]

82. Kresse, G.; Hafner, J. Ab initio molecular-dynamics simulation of the liquid-metal amorphous-semiconductor transition in germanium. Phys. Rev. B 1994, 49, 14251-14269. [CrossRef]

83. Kresse, G.; Joubert, D. From ultrasoft pseudopotentials to the projector augmented-wave method. Phys. Rev. B 1999, 59, 1758-1775. [CrossRef]

84. Blöchl, P.E. Projector augmented-wave method. Phys. Rev. B 1994, 50, 17953-17979. [CrossRef]

85. Perdew, J.P.; Burke, K.; Ernzerhof, M. Generalized gradient approximation made simple. Phys. Rev. Lett. 1996, 77, 3865-3868. [CrossRef] [PubMed] 